\title{
The Intercultural Effectiveness of University Students
}

\author{
Hugo M. Gonzales* \\ University of Notre Dame, Sydney, Australia \\ Email: hugo.gonzales@nd.edu.au, hugonzales8@gmail.com
}

How to cite this paper: Gonzales, H. M. (2017). The Intercultural Effectiveness of University Students. Psychology, 8 , 2017-2030.

https://doi.org/10.4236/psych.2017.812129

Received: August 6, 2017

Accepted: October 21, 2017

Published: October 24, 2017

Copyright $\odot 2017$ by author and Scientific Research Publishing Inc. This work is licensed under the Creative Commons Attribution International License (CC BY 4.0).

http://creativecommons.org/licenses/by/4.0/

\begin{abstract}
Intercultural communication has reached new levels with economic globalization, increased sophistication of communication technologies, and "internationalization" of education. As a critical tool for intercultural effectiveness, having a multicultural personality shapes the nature of interaction with people from other cultural backgrounds. In the university context, to advance internationalization, tertiary institutions need to be real international centers for teaching and learning with respect to people's world views. This study aimed to explore intercultural effectiveness of university students by using the Multicultural Personality Questionnaire (MPQ). With this purpose in mind, 493 students from the University of Notre Dame (ND), Sydney participated in a survey utilizing the MPQ. This study ascertained differences in dimensions of the MPQ for several demographic variables such as traditional ( $<24$ years of age) vs. non-traditional (>24 years of age) university students, gender, religious affiliation, bicultural status, and level of study. This study confirmed significant differences in intercultural effectiveness across various countries as well as gender, non-traditional students, and bicultural study. It also stressed the role of curriculum changes at universities to strengthen intercultural effectiveness.
\end{abstract}

\section{Keywords}

Intercultural Effectiveness, Multicultural Personality Questionnaire, University Teaching, Multiculturalism, Biculturalism

\section{What Is Intercultural Effectiveness?}

Intercultural effectiveness can be defined as the ability to interact and collaborate with people from diverse cultural backgrounds to enhance beneficial out${ }^{\star}$ Lecturer, Clinical Psychologist 
comes (Simkhovych, 2009). The goal of intercultural effectiveness is to minimize the risk of failure and enhance both the individual's and the organization's chances of success in an international environment. Consequently, intercultural effectiveness promotes psychological well-being and availability of social support (Van Oudenhoven \& Van der Zee, 2002). As Nesdale, Robbé, and Van Oudenhoven (2012) confirmed, intercultural effectiveness has a predictive significance in social milieus characterized by the presence of people from diverse ethnic background. In the university context, it facilitates communication and interaction between local and international students.

Another concept that has been often used interchangeably with intercultural effectiveness is intercultural competence. Intercultural competence is defined as a capability to successfully perform in intercultural encounters (Deardorff, 2006). Taylor (1994: 172-173) asserted that intercultural competence results in "perspective transformation" derived from people influencing each other and reviewing their own values through that encounter. Deardorff confirmed two elements of intercultural competence being effectiveness and appropriateness. While effectiveness is assessed by the person, competence can only be confirmed by the other person engaged in the intercultural encounter. In intercultural experiences, knowledge, skills and attitudes are important for a successful outcome (Deardorff, 2011). Knowledge may include own insight about other cultures, skills in listening and a respectful and open attitude to interact with others representing other cultures (Deardorff, 2006).

Intercultural effectiveness is of critical importance considering the need to provide education for all in the Higher Degree Education System. Student movement across cultures has contributed to universities developing internationalization policies in response to transformation of university population from monocultural to multicultural (Sawir, 2013). Most universities reflect larger community values, in particular whether people from different cultures assimilate to the mainstream society or whether people maintain their own cultural values as in the intercultural perspective (Ameny-Dixon, 2004). Australia ascribes to the second perspective, therefore, students attending universities reflect values from their own cultural backgrounds. Being in possession of a multicultural personality, therefore, has become an important attribute that may predict a successful adjustment to university for all students (Yakunina, Weigold, Weigold, Hercegovac, \& Elsayed, 2012).

To be commensurate with intercultural effectiveness, the MPQ is a valuable tool to capture several dimensions of intercultural effectiveness and related constructs such as intercultural sensitivity, intercultural competence and cultural intelligence (Simkhovych, 2009). The MPQ (Van der Zee \& Van Oudenhoven, 2000 ; 2001) is a 91-items instrument which aims to measure certain traits that correlate to intercultural success. It is considered an important tool to measure the characteristics relevant to motivational, professional and occupational problems occurring in a multicultural and/or international environment. It is a per- 
sonality assessment questionnaire built specifically to describe an individual's behavior when interacting with people from different cultures.

The development of the MPQ is rooted in the construct that cultural adaptation depends on the following five dimensions of human personality: Cultural Empathy, Open-Mindedness, Social Initiative, Emotional Stability and Flexibility.

Some of the dimensions of the MPQ (namely Emotional Stability and Social Initiative) are more related to broader adjustment to situations of stress such as being and interacting with others at university, while other dimensions such as Open-Mindedness, Flexibility and Cultural Empathy are more closely associated to adjusting to diversity in a multicultural environment (Yakunina et al., 2012).

As part of the process of adjusting to a new culture, individuals may take a bicultural position where they integrate values, beliefs and behaviors belonging to their two cultures (Nguyen \& Benet-Martínez, 2013). Biculturals present a cultural identity characterized by strength of home and receiving culture identity (Lee, 2010). Possessing a bicultural orientation is critical to adjusting to multicultural environments. Chu, White, and Verrelli (2017: 1) noted biculturalism as "experiencing two cultures simultaneously". LaFromboise, Coleman, and Gerton (1993) have contributed to this body of knowledge by suggesting that individuals with a bicultural identity will suffer less from stress, adjust better to unfamiliar cultural environments and interact better with individuals from other cultures. In practice, people with bicultural identity possess cognitive strengths to understand cultural information, make decisions associated to those cultural transactions, and maintain enthusiasm to engage in cultural transactions and confidence in cultural interactions (Lee, 2010).

\section{The Role of Teaching Intercultural Effectiveness}

Graduates entering into the workforce require a set of technical and intercultural effectiveness skills to succeed in competitive markets. As well as students possessing elements of multicultural personality, teachers' skills in intercultural effectiveness include cognitive, behavioral and emotional skills in managing multicultural classrooms (McAllister \& Irvine, 2000). Beuckelaer, Lievens, and Bucker (2012) noted that teachers who have open mindedness and cultural empathy are more successful with multicultural classes. Higher education has a role in advancing a curriculum that aims to create an educational environment supporting intercultural competence, challenging theory and history that introduces bias in textbooks, adjusting media and educational materials to diversity, providing equal opportunities for people regardless of social-financial status, and acknowledging different learning styles brought by students. In addition, it is desirable adjusting instructional delivery to meet cultural diversity, and progressing social justice values through social action principles (Ameny-Dixon, 2004).

Similarly, Stone (2006: 336) advocated for a university environment where teaching has a major contribution to multiculturalism. Stone provided the fol- 
lowing considerations relevant to assisting local and international students: a) promoting suitable teaching methods that acknowledge cultural diversity in class; b) appropriate curriculum programs and provision of services for a multicultural student university population; c) matching curriculum with demands of an international professional market; d) ensuring a social university environment that supports diversity; e) international collaboration in teaching and research; and f) a university environment that promotes "global citizenship" competencies for staff and students.

This research aims to ascertain how interculturally effective ND students are. Intercultural effectiveness is a combination of previous learning, skills being developed at the university as well as personality attributes such as emotional intelligence, motivation, and openness during intercultural experiences. Therefore, a university has a major role in moulding an interculturally effective university student. This study will use the MPQ to explore degree of intercultural effectiveness of ND students. It aims to also confirm the influence of demographic variables such as age, gender, level of study, course of study, bicultural status, and religious affiliation on levels of intercultural effectiveness.

\section{Methodology}

\subsection{Research Instruments}

The MPQ first administered to Dutch students demonstrated a five-scale reliability (all the subscales were above 0.70 ). Incremental validity and construct validity of the subscales of the MPQ were also supported. The MPQ has also been tested in their validity across cultures, and the MPQ has been able to be generalized across different cultural groups. A study completed with Italian and Dutch samples demonstrated that the five dimensions are stable across samples from different cultures (Leone, Van der Zee, van Oudenhoven, Perugini, \& Ercolani, 2005).

The MPQ is a 91-items instrument assessing five dimensions of Multicultural Personality including Cultural Empathy, Open-Mindedness, Social Initiative, Emotional Stability, and Flexibility. These items are valued using the five multicultural dimensions rated on a five point Likert scale (1-totally not applicable to 5-completely applicable). Each dimension of the MPQ includes items that describe specific behaviors or trends for each behavior dimension.

The five personality factors assessed by the MPQ are described by Leone et al. (2005: 1450-1451) as follows:

1) Cultural Empathy (CE, 18 items): This is the most frequently mentioned dimension of Cultural Effectiveness (Arthur \& Bennett, 1995). People with high scores for Cultural Empathy identify themselves easily with the feelings, thoughts and behaviors of individuals and groups belonging to different cultures.

2) Open-Mindedness (O, 18 items): This dimension scale assesses people's ability to be open and non-judgmental when faced with other people outside their cultural group that may have different values and norms. 
3) Social Initiative (SI, 17 items): Individuals who have a high social initiative score are easily able to build up social networks and lead social action in a multicultural environment. They actively address social situations and take the initiative.

In addition, this dimension takes into consideration personality characteristics such as: extraversion, sociability, and action tendency.

4) Emotional Stability (ES, 20 items): This dimension's scale assesses the degree to which people tend to stay composed in stressful situations and environments. Leaving the home country and trying to adapt to a new cultural environment has been identified as a stressful situation by many individuals. This dimension is negatively linked to neuroticism (Hendriks, Hofstee, \& De Raad, 1999).

5) Flexibility (F, 18 items): This behavior dimension scale is associated with people's ability to adapt their behavior to unfamiliar situations that promote adaptation to the new cultural environment. It focuses on characterizing the flexibility in the way new professional procedures and tasks are tackled.

\subsection{Data Preparation}

Data was arranged to include a traditional university student sample that is typically a 24 years and under age group completing university studies, and an over 24 years of age group that represents a non-traditional university student sample group. In terms of race, for clarity of data, the overall group was subdivided into a large Caucasian section and another non-Caucasian minor sample.

\section{Parametric and Non-Parametric Treatment of Data}

Anova analysis was conducted for Open-Mindedness, Emotional Initiative and Flexibility. Due to the presence of non-normally distributed data, independent samples non-parametric analysis was performed for Cultural Empathy and Social Initiative. In addition, MPQ data for these two dimensions of CE and SI were not homogeneous.

\subsection{Participants and Sample Size}

Four hundred and ninety-three respondents completed a survey forwarded to 4900 students currently studying at one of five university Faculties at the Sydney campus of the University of Notre Dame. This represents approximately $10 \%$ of the overall student population. Respondents completed the MPQ and demographic information.

Male participants represented $21.9 \%$ of the sample and females represented $78.1 \%$. In terms of the traditional population attending university i.e. those students between 18 - 24 years represented $70.6 \%$ of the sample. The non-traditional (based on age) group was represented by 25 - 34 years (15.5\%), 35 - 44 years (5.8\%), 45 - 54 years $(5.2 \%)$, and 55 years and over $(2.9 \%)$. In terms of religion, the sample comprised Catholics (39.4\%), Christians (24.3\%), non-religion (20.5\%), and 
other (15.8\%). In terms of marital status, single (64\%), not married but living with a significant other (21.9\%), married (9.7\%), divorced/separated (4.1\%), and widowed (0.2\%). Level of study was distributed amongst first year (37.6\%), second year (23.8\%), third year (16.9), and fourth year (12.6\%) of studies. In terms of faculty of study, the distribution was Arts and Sciences (22.7\%), Education (31.2\%), Nursing (21.1\%), Business (6.4\%), Medicine (6\%), Philosophy and Theology (4.3\%), and other (2.9\%).

The sample of respondents was mostly those enrolled in first to third year of studies. Most students had fathers and mothers who had completed some level of university education. The majority of subjects were female $(\mathrm{N}=378)$ compared to males $(\mathrm{N}=106)$, and single $(\mathrm{N}=356)$ compared to married $(\mathrm{N}=128)$. Student sample was selected from a Catholic University resulting in a large portion of the respondents being Christian or Catholic. The majority of students were Caucasians $(\mathrm{N}=302)$ compared to non-Caucasians $(\mathrm{N}=182)$. A large section of the student sample spoke English language at home $(\mathrm{N}=413)$ compared to non-English $(\mathrm{N}=71)$. Similarly, language spoken as a child was mostly English $(\mathrm{N}=350)$ compared to non-English language $(\mathrm{N}=134)$. Language spoken currently at home and language spoken as a child have been considered as indicators of acculturation and bicultural status (Wallen, Feldman, \& Anliker 2002).

\section{Results}

\section{MPQ means for Australian and other country student groups}

The MPQ means for results for five subscales for ND students were compared with other international studies that sampled university students. ND students were different to all groups compared including samples from the Netherlands (Van der Zee, Zaal, \& Piekstra, 2003, 88) USA (Houtz, Ponterotto, Burger, \& Cherylynn, 2010: 934) and Romania (Popescu, Borca, \& Baesu, 2014: 155). Comparing subscales of the MPQ across cultures, mean differences were significant when comparing ND students with all groups. Cultural Empathy was not significant between ND and the Netherlands sample, and with Romanians Flexibility was not significant (Please see Table 1).

\section{MPQ Subscales and Demographic data}

This section presents findings from each of the five subscales of the MPQ with

Table 1. Comparing means for MPQ across cultures.

\begin{tabular}{lcccc}
\hline & This study & Netherlands & USA & Romania \\
\hline Subscales & $\mathrm{M}$ & $\mathrm{M}$ & $\mathrm{M}$ & $\mathrm{M}$ \\
Cultural Empathy & 4.00 & 3.99 & 4.24 & 3.56 \\
Open-Mindedness & 3.69 & 3.80 & 3.76 & 3.46 \\
Emotional Stability & 2.99 & 3.94 & 3.13 & 3.34 \\
Social Initiative & 3.38 & 3.87 & 3.65 & 3.20 \\
Flexibility & 3.08 & 3.41 & 3.15 & 3.10 \\
\hline
\end{tabular}


relevant demographic variables in this study. Parametric t-tests and non-parametric independent sample test were performed with the data.

Female students $(M=4.03)$ were significantly higher $(p=0.01)$ than Male students $(\mathrm{M}=3.89)$ on Cultural Empathy (Please see Table 2$)$.

Non-traditional students $(M=3.77)$ presented significant differences $(p=$ $0.01)$ when compared with traditional students $(M=3.65)$ on Open Mindedness. In terms of main language at home, non-English speaking students $(M=3.8)$ were significantly different $(p=0.031)$ than students who spoke English at home $(\mathrm{M}=3.67)$ on Open Mindedness.

For language spoken at home currently, there are significant differences in Open-Mindedness where students who speak other than English language currently at home are more open-minded than those who speak English $p=0.0031$ on Open Mindedness (Please see Table 3).

Non-traditional students $(\mathrm{M}=3.55)$ presented significant differences $(p=0.0)$ when compared with traditional students $(M=3.31)$ on Social Initiative. In terms of marital status, single students $(\mathrm{M}=3.49)$ were significantly different ( $p$ $=0.0)$ than married students $(M=3.33)$ on Social Initiative (Please see Table 4).

Non-traditional students $(M=3.16)$ presented significant differences $(p=0.0)$ when compared with traditional students $(M=2.91)$ on Emotional Stability. In

Table 2. Cultural Empathy-Non-parametric independent sample test: demographics and dimensions of MPQ.

\begin{tabular}{|c|c|c|c|c|c|}
\hline & $\mathrm{n}$ & M & SD & $\mathrm{Md}$ & $P$ \\
\hline \multicolumn{6}{|l|}{ Age } \\
\hline Traditional & 342 & 3.98 & 0.42 & 4 & 0.2 \\
\hline Non-traditional & 142 & 4.08 & 0.47 & & \\
\hline \multicolumn{6}{|l|}{ Gender } \\
\hline Female & 378 & 4.03 & 0.42 & 4 & 0.01 \\
\hline Male & 106 & 3.89 & 0.49 & & \\
\hline \multicolumn{6}{|l|}{ Marital status } \\
\hline Single & 356 & 4.02 & 0.49 & 4 & 0.38 \\
\hline Married & 128 & 3.99 & 0.42 & & \\
\hline \multicolumn{6}{|l|}{ Race } \\
\hline Caucasian & 302 & 3.94 & 0.46 & 4 & 0.34 \\
\hline Non-Caucasian & 182 & 4.04 & 0.42 & & \\
\hline \multicolumn{6}{|l|}{ Childhood language } \\
\hline English & 350 & 3.99 & 0.44 & 4 & 0.66 \\
\hline Other than English & 134 & 4.02 & 0.44 & & \\
\hline \multicolumn{6}{|c|}{ Main language at home } \\
\hline English & 413 & 3.99 & 0.44 & 4 & 0.24 \\
\hline Other than English & 71 & 4.06 & 0.42 & & \\
\hline
\end{tabular}


Table 3. Open-Mindedness- $t$ test on demographics and dimensions of MPQ.

\begin{tabular}{lcccccc}
\hline & $\mathrm{n}$ & $\mathrm{M}$ & $\mathrm{SD}$ & $\mathrm{Md}$ & $\mathrm{t}$ & $P$ \\
\hline Age & & & & & & \\
Traditional & 342 & 3.65 & 0.48 & 3.67 & -2.48 & 0.01 \\
Non-traditional & 142 & 3.77 & 0.47 & & & \\
Gender & & & & & & \\
Female & 378 & 3.67 & 0.48 & 3.67 & -0.34 & 0.73 \\
Male & 106 & 3.69 & 0.48 & & & \\
Marital status & & & & & & \\
Single & 356 & 3.67 & 0.47 & 3.67 & 0.75 & 0.45 \\
Married & 128 & 3.71 & 0.48 & & & \\
Race & & & & & & \\
Caucasian & 302 & 3.66 & 0.46 & 3.67 & -0.97 & 0.33 \\
Non-Caucasian & 182 & 3.71 & 0.51 & & & \\
Childhood language & & & & & & \\
English & 350 & 3.66 & 0.49 & 3.67 & -1.63 & -0.79 \\
Other than English & 134 & 3.74 & 0.45 & & & \\
Main language at home & & & & & & \\
English & 413 & 3.67 & 0.48 & 3.67 & -2.16 & 0.031 \\
Other than English & 3.8 & 0.42 & & & \\
\hline & & & & & & \\
\hline
\end{tabular}

Table 4. Social Initiative-Non-parametric independent sample test: demographics and dimensions of MPQ.

\begin{tabular}{|c|c|c|c|c|c|}
\hline & $\mathrm{n}$ & $\mathrm{M}$ & SD & $\mathrm{Md}$ & $P$ \\
\hline \multicolumn{6}{|l|}{ Age } \\
\hline Traditional & 342 & 3.31 & 0.47 & 3.41 & 0 \\
\hline Non-traditional & 142 & 3.55 & 0.52 & & \\
\hline \multicolumn{6}{|l|}{ Gender } \\
\hline Female & 378 & 3.38 & 0.49 & 3.41 & 0.79 \\
\hline Male & 106 & 3.36 & 0.5 & & \\
\hline \multicolumn{6}{|l|}{ Marital status } \\
\hline Single & 356 & 3.49 & 0.47 & 3.41 & 0 \\
\hline Married & 128 & 3.33 & 0.5 & & \\
\hline \multicolumn{6}{|l|}{ Race } \\
\hline Caucasian & 302 & 3.35 & 0.46 & 3.41 & 0.28 \\
\hline Non-Caucasian & 182 & 3.39 & 0.41 & & \\
\hline \multicolumn{6}{|l|}{ Childhood language } \\
\hline English & 350 & 3.39 & 0.49 & 3.41 & 0.74 \\
\hline Other than English & 134 & 3.36 & 0.51 & & \\
\hline \multicolumn{6}{|c|}{ Main language at home } \\
\hline English & 413 & 3.38 & 0.5 & 3.41 & 0.64 \\
\hline Other than English & 71 & 3.35 & 0.48 & & \\
\hline
\end{tabular}


Table 5. Emotional Stability—t test on demographics and dimensions of MPQ.

\begin{tabular}{|c|c|c|c|c|c|c|}
\hline & $\mathrm{n}$ & $\mathrm{M}$ & SD & $\mathrm{Md}$ & $\mathrm{t}$ & $P$ \\
\hline \multicolumn{7}{|l|}{ Age } \\
\hline Traditional & 342 & 2.91 & 0.47 & 2.9 & -4.68 & 0 \\
\hline Non-traditional & 142 & 3.16 & 0.55 & & & \\
\hline \multicolumn{7}{|l|}{ Gender } \\
\hline Female & 378 & 2.92 & 0.49 & 2.9 & -5.68 & 0 \\
\hline Male & 106 & 3.22 & 0.48 & & & \\
\hline \multicolumn{7}{|l|}{ Marital status } \\
\hline Single & 356 & 2.98 & 0.52 & 2.9 & 0.79 & 0.43 \\
\hline Married & 128 & 3.02 & 0.48 & & & \\
\hline \multicolumn{7}{|l|}{ Race } \\
\hline Caucasian & 302 & 2.97 & 0.52 & 2.9 & -1.3 & 0.19 \\
\hline Non-Caucasian & 182 & 3.03 & 0.48 & & & \\
\hline \multicolumn{7}{|l|}{ Childhood language } \\
\hline English & 350 & 2.99 & 0.52 & 2.9 & -1.63 & 0.8 \\
\hline Other than English & 134 & 2.98 & 0.46 & & & \\
\hline \multicolumn{7}{|c|}{ Main language at home } \\
\hline English & 413 & 2.99 & 0.52 & 2.9 & 0.98 & 0.33 \\
\hline Other than English & 71 & 2.94 & 0.42 & & & \\
\hline
\end{tabular}

terms of gender, male students $(M=3.22)$ were significantly different $(p=0.0)$ than female students $(M=2.92)$ on Emotional Stability (Please see Table 5$)$.

Non-traditional students $(M=3.14)$ presented significant differences $(p=$ $0.03)$ when compared with traditional students $(M=3.05)$ on Flexibility. In terms of childhood language, English speaking students $(M=3.1)$ were significantly different $(p=0.07)$ than non-English speaking students $(\mathrm{M}=3.02)$ on Flexibility (Please see Table 6).

\section{Discussion and Conclusion}

Females are more attuned to their emotions and studies have confirmed that they may present more emotional intelligence attributes than men (Cabello, Sorrel, Fernandez-Pinto, Extremera, \& Fernandez-Berrocal, 2016). Research has indicated that they may seek emotional support when required as they have a good capacity in perceiving, understanding and managing emotions (Cabello et al., 2016). Consequently, it is not surprising that women are more culturally empathic than men. Previous research has confirmed that sex difference in emotional intensity derived from sex-differentiated normative pressures, specify that women are more emotionally responsive than men (Grossman \& Wood, 1993). In this study, men were surprisingly more emotionally stable than women, and women were more culturally empathic than men. 
Table 6. Flexibility_t test on demographics and dimensions of MPQ.

\begin{tabular}{|c|c|c|c|c|c|c|}
\hline & $\mathrm{n}$ & M & SD & $\mathrm{Md}$ & $\mathrm{t}$ & $P$ \\
\hline \multicolumn{7}{|l|}{ Age } \\
\hline Traditional & 342 & 3.05 & 0.44 & 3.06 & -2.17 & 0.03 \\
\hline Non-traditional & 142 & 3.14 & 0.41 & & & \\
\hline \multicolumn{7}{|l|}{ Gender } \\
\hline Female & 378 & 3.09 & 0.45 & 3.06 & 0.28 & 0.78 \\
\hline Male & 106 & 3.07 & 0.39 & & & \\
\hline \multicolumn{7}{|l|}{ Marital status } \\
\hline Single & 356 & 3.08 & 0.45 & 3.06 & 0.38 & 0.71 \\
\hline Married & 128 & 3.09 & 0.39 & & & \\
\hline \multicolumn{7}{|l|}{ Race } \\
\hline Caucasian & 302 & 3.09 & 0.47 & 3.06 & 0.93 & 0.35 \\
\hline Non-Caucasian & 182 & 3.06 & 0.37 & & & \\
\hline \multicolumn{7}{|l|}{ Childhood language } \\
\hline English & 350 & 3.1 & 0.45 & 3.06 & 0.33 & 0.07 \\
\hline Other than English & 134 & 3.02 & 0.41 & & & \\
\hline \multicolumn{7}{|c|}{ Main language at home } \\
\hline English & 413 & 3.09 & 0.44 & 3.06 & 0.82 & 0.45 \\
\hline Other than English & 71 & 3.04 & 0.41 & & & \\
\hline
\end{tabular}

Age recoded into 4 variables was significant for Emotional Stability with older groups from 35 - 44 and 45 and over having higher Emotional Stability than younger groups, $p=0.0$. This was also the case for Social Initiative, $p=0.0$. Age recoded into 4 variables was significant for emotional stability with older groups from 35 - 44 and 45 and over having higher Emotional Stability than younger groups, $p=0.0$. This was also true for Social Initiative, $p=0.0$. Non-traditional students i.e. those who are older than 24 were more emotionally stable than younger traditional university students. Interestingly, in this study there were significant differences for gender on Emotional Stability where males appeared more emotionally stable than females, $p=0.0$. Married students were more emotionally stable than single students.

Age appears to account for significant differences across various dimensions of the MPQ. Non-traditional (>24 years) students juggling study, family and paid-work represent an increasing section of the university population. Their experience in the workforce provides them with personal attributes that place them in an advantageous position for a successful journey at university (Ellis, 2013). Non-traditional students maturity also provides them with Open-Mindedness, Emotional Stability, Social Initiative and Flexibility not so developed yet for traditional students ( $<24$ years). The experience of non-traditional students in the classroom context might be useful for traditional students as they may benefit 
from group partnering and mentoring strategies from the non-traditional students, thereby enhancing their success across different dimensions of the MPQ. It is interesting that there are no differences for Cultural Empathy across age groups. Regardless of age, ND students have a healthy Cultural Empathy. This may be an expression of the multicultural nature of Australian society, where everyone is exposed to multiculturalism throughout developmental periods (Moran, 2016). It may also be linked to ND's promotion of values of social justice, moral and ethical professional behavior, and empathy with others from early stages of the student experience with their course of studies.

Research has extensively reviewed the Cultural Empathy dimension of the MPQ. This study has confirmed the robustness of Cultural Empathy for the ND sample. Previous studies have determined strength of relationship between Cultural Empathy and Index of Cultural Intelligence (CQ). It is important to convey that CQ correlates negatively with ethnocentrism, thus this sample studied with a high Cultural Empathy, represents a healthy section of the population (Ahmadi, Shahmohamadi, \& Mahdi, 2011).

There were no differences in IE between undergraduate and postgraduate students. This is an interesting finding as it was anticipated that as students progress in their studies they become more IE. Students may use some dimensions of their MPQ earlier in their studies, e.g. Cultural Empathy and others later, e.g. Flexibility. Early in their studies, students may approach others from more observational skills and later from a more integrative perspective.

Adhering to a religious faith did not influence means for the MPQ. It is assumed that all have a role in moulding a multicultural stance. This confirms the importance of distancing from religious prejudice, particularly for youths in university settings. As Gawali and Khattar (2016) have suggested, it is critical to mentor students in inter-religious harmony and multiculturalism.

Bicultural students from a non-Caucasian background, speaking a language other than English at home, may as expected, present as more IE than those without these attributes. Their interaction with others, as highlighted by LaFromboise, Coleman, and Gerton (1993) is less stressful, and bicultural students exhibit more flexibility in these encounters.

Deardorff (2006) has emphasized the role of tertiary education in shaping intercultural effectiveness for students and their lifelong pursuit journey towards intercultural effectiveness. Consequently, academics at university have a crucial role in providing proactive support to internationalization and effectiveness of their students. Strategies in class may therefore be added to evaluating outcomes in the community such as client satisfaction, increased utilization of services and improved health status (Brach \& Fraser, 2000).

Intercultural teaching skills programs are becoming innovative methods to increase self-efficacy. One of these programs is the Excellence in Experiential Learning and Leadership (EXCELL). Studies on the application of this program increased strength in Open-Mindedness, Social Initiative and Emotional Stabili- 
ty. Furthermore, students reported increased confidence and friendships both in the classroom and in the broader community (Mak Westwood, Ishiyama, \& Barker, 1999).

Effective teaching should encompass personality differences in the student population e.g. sensing vs. intuitive; as well as accommodating for new learning opportunities for teachers themselves. However, a mix of experiential case scenarios in class and practical activities linked to intercultural interactions will facilitate multicultural learning for all. It is suggested that experiential activities around the issues of intercultural effectiveness modelled by instructors may have a greater impact on university students than just delivering content in classrooms (Browne \& Mokuau, 2008).

Students approach learning based on their Multicultural Personality style and these students from Law, Business and Medicine will bring a different set of personality attributes, thus a more inclusive teaching is required (Seddigi, Capretz, \& House, 2009). The fact that this study did not present significant differences on MPQ based on Faculty of Studies only confirms personality types adjusting to a more multicultural workplace and demands on the professions.

In conclusion, as suggested by Salmona, Partlo, Kaczynski, and Leonard (2015), it is recommended that universities promoting organizational change towards a more culturally inclusive teaching delivery, need to integrate changes in program curriculum reflective of this outcome. It is also important that universities provide an environment inclusive of all students and as Leask (2001: 114 ) suggested, university staff need to focus more on process rather than content.

\section{References}

Ahmadi, Y., Shahmohamadi, A., \& Mahdi, M. M. (2011). The Study of Effect of Socio-Cultural Factor on Cultural Intelligence (CQ) (Case Study: Sanandaj City). International Journal of Humanities and Social Science, 1, 161-168.

Ameny-Dixon, G. M. (2004). Why Multicultural Education Is More Important in Higher Education Now than Ever: A Global Perspective. International Journal of Scholarly Academic Intellectual Diversity, 6, 1-12.

Arthur Jr., W., \& Bennett Jr., W. (1995). The International Assignee: The Relative Importance of Factors Perceived to Contribute to Success. Personnel Psychology, 48, 99-114.

Beuckelaer, A. D., Lievens, F., \& Bucker, J. (2012). The Role of Faculty Members' Cross-Cultural Competencies in Their Perceived Teaching Quality: Evidence from Culturally-Diverse Classes in Four European Countries. Journal of Higher Education, $83,217-248$.

Brach, C., \& Fraser, I. (2000). Can Cultural Competency Reduce Racial and Ethnic Health Disparities? A Review and Conceptual Model. Medical Care Research and Review, 57, 181-217. https://doi.org/10.1177/1077558700057001S09

Browne, C. V., \& Mokuau, N. (2008). Preparing Students for Culturally Competent Practice among Ethnic Minority Elders. Educational Gerontology, 34, 306-327. https://doi.org/10.1080/03601270701834018

Cabello, R., Sorrel, M. A., Fernandez-Pinto, I., Extremera, N., \& Fernandez-Berrocal P. 
(2016). Age and Gender Differences in Ability Emotional Intelligence in Adults: A Cross-Sectional Study. Developmental Psychology, 52, 1486-1492.

https://doi.org/10.1037/dev0000191

Chu, E., White, F. A., \& Verrelli, S. (2017). Biculturalism amongst Ethnic Minorities: Its Impact for Individuals and Intergroup Relations: Biculturalism. Australian Journal of Psychology. (In press)

Deardorff, D. K. (2006). Identification and Assessment of Intercultural Competence as a Student Outcome of Internationalization. Journal of Studies in International Education, 10, 241-266. https://doi.org/10.1177/1028315306287002

Deardorff, D. K. (2011). Assessing Intercultural Competence. New Directions for Institutional Research, 149, 65-79.

Ellis, B. J. (2013). Older Undergraduate Students Bringing Years of Experience to University Studies: Highlights, Challenges and Contributions. Australian Journal of Adult Learning, 53, 351.

Gawali, G., \& Khattar, T. (2016). The Influence of Multicultural Personality on Attitude towards Religious Diversity among Youth. Journal of the Indian Academy of Applied Psychology, 42, 114-123.

Grossman, M., \& Wood, W. (1993). Sex Differences in Intensity of Emotional Experience: A Social Role Interpretation. Journal of Personality and Social Psychology, 65, 1010-1022. https://doi.org/10.1037/0022-3514.65.5.1010

Hendriks, A. A. J., Hofstee, W. K., \& De Raad, B. (1999). The Five-Factor Personality Inventory (FFPI). Personality and Individual Differences, 27, 307-325.

Houtz, J. C., Ponterotto, J. G., Burger, C., \& Cherylynn, M. (2010), Problem Solving Style and Multicultural Personality Dispositions: A Study of Constructive Validity. Psychological Reports, 36, 927-937. https://doi.org/10.2466/pr0.106.3.927-938

LaFromboise, T., Coleman, H. L. K., \& Gerton, J. (1993). Psychological Impact of Biculturalism: Evidence and Theory. Psychological Bulletin, 114, 395-412.

https://doi.org/10.1037/0033-2909.114.3.395

Leask, B. (2001). Bridging the Gap: Internationalizing University Curricula. Journal of Studies in International Education, 5, 100-115. https://doi.org/10.1177/102831530152002

Lee, Y.-T. (2010). Home versus Host-Identifying with Either, Both, or Neither? The Relationship between Dual Cultural Identities and Intercultural Effectiveness. International Journal of Cross Cultural Management, 10, 55-76.

https://doi.org/10.1177/1470595809359583

Leone, L., Van der Zee, K. I., van Oudenhoven, J. P., Perugini, M., \& Ercolani, A. P. (2005). The Cross-Cultural Generalizability and Validity of the Multicultural Personality Questionnaire. Personality and Individual Differences, 38, 1449-1462.

Mak, A. S., Westwood, M. J., Ishiyama, F. I., \& Barker, M. C. (1999). Optimising Conditions for Learning Sociocultural Competencies for Success. International Journal of Intercultural Relations, 23, 77-90.

McAllister, G., \& Irvine, J. J. (2000). Cross Cultural Competency and Multicultural Teacher Education. Review of Educational Research, 70, 3-24.

http://www.jstor.org.ipacez.nd.edu.au/stable/1170592

https://doi.org/10.3102/00346543070001003

Moran, L. (2016). Constructions of Race: Symbolic Ethnic Capital and the Performance of Youth Identity in Multicultural Australia. Ethnic and Racial Studies, 39, 708-708. https://doi.org/10.1080/01419870.2015.1080375 
Nesdale, W., Robbe, M. D. V., \& Van Oudenhoven, J. P. (2012). Intercultural Effectiveness, Authoritarianism, and Ethnic Prejudice. Journal of Applied Social Psychology, 42, 1173-1191. https://doi.org/10.1111/j.1559-1816.2011.00882.x

Nguyen, A.-M. D., \& Benet-Martínez, V. (2013). Biculturalism and Adjustment: A Meta-Analysis. Journal of Cross-Cultural Psychology, 44, 122-159. https://doi.org/10.1177/0022022111435097

Popescu, A.-D., Borca, C., \& Baesu, V. (2014). A Study on Multicultural Personality. Cross-Cultural Management Journal, 16, 147-156.

Salmona, M., Partlo, M., Kaczynski, D., \& Leonard, S. N. (2015). Developing Culturally Competence Teachers: An International Student Teaching Field Experience. Australian Journal of Teacher Education, 40, 35-53.

Sawir, E. (2013). International Students and Internationalisation of Higher Education. Journal of International Students, 3, III.

Seddigi, Z. S., Capretz, L. F., \& House, D. (2009). A Multicultural Comparison of Engineering Students: Implications to Teaching and Learning. Journal of Social Sciences, 5, 117-122. https://doi.org/10.3844/jssp.2009.117.122

Simkhovych, D. (2009). The Relationship between Intercultural Effectiveness and Perceived Project Team Performance in the Context of International Development. International Journal of Intercultural Relations, 33, 383-390.

Stone, N. (2006). Conceptualising Intercultural Effectiveness for University Teaching. Journal of Studies in International Education, 10, 334-356. https://doi.org/10.1177/1028315306287634

Taylor, E. W. (1994). Intercultural Competency: A Transformative Learning Process. Adult Education Quarterly, 44, 154-174. https://doi.org/10.1177/074171369404400303

Van Der Zee, K. I., \& Oudenhoven, J. P. V. (2000). The Multicultural Personality Questionnaire: A Multidimensional Instrument of Multicultural Effectiveness. European Journal of Personality, 14, 291-309. https://doi.org/10.1002/1099-0984(200007/08)14:4<291::AID-PER377>3.0.CO;2-6

Van Der Zee, K. I., \& Van Oudenhoven, J. P. (2001). The Multicultural Personality Questionnaire: Reliability and Validity of Self- and Other Ratings of Multicultural Effectiveness. Journal of Research in Personality, 35, 278-288. https://doi.org/10.1006/jrpe.2001.2320

Van der Zee, K. I., Zaal, J. N., \& Piekstra, J. (2003). Validation of the Multicultural Personality Questionnaire in the Context of Personnel Selection. European Journal of Personality, 17, 77-100. https://doi.org/10.1002/per.483

Van Oudenhoven, J. P., \& Van der Zee, K. I. (2002). Predicting Multicultural Effectiveness in International Students: The Multicultural Personality Questionnaire. International Journal Intercultural Relations, 26, 679-694.

Wallen, G. R., Feldman, R. H., \& Anliker, J. (2002). Measuring Acculturation among Central American Women with the Use of a Brief Language Scale. Journal of Immigrant Health, 4, 95. https://doi.org/10.1023/A:1014550626218

Yakunina, E. S., Weigold, I. K., Weigold, A., Hercegovac, S., \& Elsayed, N. (2012). The Multicultural Personality: Does It Predict International Students' Openness to Diversity and Adjustment? International Journal of Intercultural Relations, 36, 533-540. 